\title{
A clinical approach to the use of methotrexate for sarcoidosis
}

\author{
Robert P Baughman, Elyse E Lower
}

The management of patients with sarcoidosis has been the subject of many papers in this ${ }^{1}$ and other journals. ${ }^{2-5}$ The large number of papers are, in part, because of the difficulty in defining who should be treated for this disease and with what. The most commonly used pharmaceutical class for sarcoidosis has been corticosteroids, both topically and systemically. ${ }^{6}$ The use of systemic steroids for sarcoidosis was the subject of a trial by the British Thoracic Society ${ }^{1}$ which concluded that there were some patients who required no treatment and some who would need immediate treatment because of the severity of the disease. In between was a group of patients with persistent disease who appeared to benefit from treatment with corticosteroids. One of the points made was that some patients needed treatment for long periods of time.

The term "chronic sarcoidosis" has been used by Dr Geraint James to describe patients with disease for more than two years. ${ }^{7}$ He noted that some features of sarcoidosis such as lupus pernio and neurological disease were associated with a low rate of remission, while other features such as erythema nodosum were associated with a high resolution rate by two years. Several other manifestations of the disease have been associated with chronic disease: bone cysts, cor pulmonale, pulmonary fibrosis, ${ }^{8}$ and nephrolithiasis. ${ }^{9}$ Based on the type and duration of symptoms one can classify patients as acute or chronic. ${ }^{10} \mathrm{~A}$ third group is also evident-namely, those who are refractory to corticosteroid therapy. This includes some neurosarcoidosis patients, patients who develop organ failure, and those who die despite corticosteroid treatment. ${ }^{11}{ }^{12}$ Treatment for sarcoidosis is often dependent on the patient's own manifestation. A patient with anterior uveitis may be a candidate for topical steroids alone, but a patient with neurological disease may need chronic high dose corticosteroids to control the disease. ${ }^{13}$ Patients in the chronic category have been interested for years in taking alternatives to corticosteroids. Fortunately, a group of agents has been used as steroid sparing agents in sarcoidosis..$^{1015}$ We will discuss the use of one of these, methotrexate.

The first report of methotrexate in the treatment of sarcoidosis was over 30 years ago. ${ }^{16}$ The drug was initially used for chronic cases. Although it was sometimes effective, clinicians would usually limit treatment to six months because of concerns about the toxic effects of the agent, particularly bone marrow suppression and hepatotoxicity. ${ }^{17}$ Methotrexate has been used widely in rheumatoid arthritis and experience with the agent in both adults and children has demonstrated its relative safety. ${ }^{18-21}$ In these patients the toxicity from methotrexate was predictable and guidelines for monitoring the agent became available. ${ }^{22}$

We became interested in the use of methotrexate for sarcoidosis over 10 years ago. The original patients had been on corticosteroids for many years (range 2-23 years, median 5 years) and wished to try an alternative agent. ${ }^{23}$ In some cases we had patients who refused to take prednisone again despite advancing disease. In our first 15 patients it was clear that methotrexate was an agent that took some time to be effective. For the majority of patients objective evidence of response to treatment could take as long as six months, although subjective improvement was sometimes seen sooner. Thus, the recommendation that the drug should be withdrawn after six months meant that patients would be perceived as not responding simply because they had not received the drug for sufficient time.

Because of this clinical response we studied the inflammatory response to methotrexate compared with prednisone in patients with sarcoidosis. ${ }^{24}$ In sarcoidosis the researcher has the unique opportunity to examine the inflammatory cells in the organ affected by the disease. Bronchoalveolar lavage (BAL) has provided a large amount of information regarding interstitial lung diseases, especially sarcoidosis. $^{25}$ The BAL fluid of a patient with active sarcoidosis usually contains an increased percentage of $\mathrm{T}$ lymphocytes, usually CD4+ cells. ${ }^{26}$ In addition, the alveolar macrophages retrieved by BAL from patients with sarcoidosis are activated and release various products including hydrogen peroxide and tumour necrosis factor (TNF). ${ }^{27}$ In our study patients with active sarcoidosis were treated with either prednisone or methotrexate and the clinical and inflammatory response was measured. Patients were treated for at least six months with either agent. There was a significant improvement in the vital capacity over this time period for both drugs. The increased number of lymphocytes found in the BAL fluid of patients with active sarcoidosis fell significantly with treatment with either agent, and the CD4:CD8 ratio became closer to normal (table 1). The spontaneous release of TNF was again seen from the alveolar macrophages retrieved by BAL in patients with active sarcoidosis. This also fell with treatment in both the prednisone and methotrexate groups. ${ }^{24}$ This study was neither blinded nor randomised. Some patients treated with methotrexate also received low dose corticosteroids.

Several studies have demonstrated the value of methotrexate in patients with refractory disease. These are summarised in table 2. Many of 
Table 1 Mean (SE) results of methotrexate versus prednisone in sarcoidosis ${ }^{24}$

\begin{tabular}{|c|c|c|c|c|}
\hline & \multicolumn{2}{|l|}{ Methotrexate } & \multicolumn{2}{|l|}{ Prednisone } \\
\hline & $\begin{array}{l}\text { Before } \\
\text { treatment }\end{array}$ & $\begin{array}{l}\text { After } \\
\text { treatment }\end{array}$ & $\begin{array}{l}\text { Before } \\
\text { treatment }\end{array}$ & $\begin{array}{l}\text { After } \\
\text { treatment }\end{array}$ \\
\hline \multirow{4}{*}{$\begin{array}{l}\text { Vital capacity (1) } \\
\text { BAL lymphocyte (\%) } \\
\text { BAL lymphocyte CD } 4: \text { CD } 8 \\
\text { Macrophage TNF release } \\
\quad \text { (units } / 10^{6} \text { cells) }\end{array}$} & $2.4(0.14)$ & $2.8(0.18) \dagger$ & $2.5(0.14)$ & $3.1(0.18) \dagger$ \\
\hline & $37 \quad(3.4)$ & $16 \quad(2.7) t$ & $30(3.5)$ & $16(2.7) t$ \\
\hline & $7.4(2.69)$ & $4.0(1.90)$ & $7.3(1.52)$ & $3.3(0.67)$ \\
\hline & 111 & $24 \quad(15.4) \ddagger$ & $89 \quad(29.2)$ & $18 \quad(9.2) \ddagger$ \\
\hline
\end{tabular}

$\mathrm{BAL}=$ bronchoalveolar lavage $\mathrm{TNF}=$ tumour necrosis factor.

$\mathrm{tp}<0.001, \neq \mathrm{p}<0.05$ versus before treatment.

these reports concerned a few cases with chronic disease. The most common manifestations include skin disease, especially lupus pernio. The response rate for skin disease appears high. The patients with lung disease are less likely to respond, with about half of patients reporting some response. One difficulty with these case reports is the fact that one does not have a sense of how many cases did not respond to treatment. One group reported on their use of methotrexate with both corticosteroids and cyclosporin. ${ }^{29}$ Although there was a good clinical response, it was not clear how much the methotrexate contributed to the effectiveness. It was the best tolerated of the three drugs given.

In a study of paediatric sarcoidosis, children received methotrexate following a strict protocol. ${ }^{30}$ Corticosteroids were used for the first weeks only in six of seven cases. They were treated with methotrexate for one year and the clinical response was scored using a composite of the various symptoms encountered. The methotrexate was associated with a significant improvement in the clinical score compared with placebo alone. One criticism of this study is the use of a clinical score rather than objective measurements. ${ }^{31}$ However, most patients have a multisystem disease, with many of the symptoms being subjective. These include fatigue, myalgias, and pain, and are true symptoms for the patient, representing indications for treatment.

We have treated a large number of patients with methotrexate. ${ }^{13} 3233$ Table 3 summarises our experience with the clinical response in 50 patients treated for at least two years. ${ }^{32}$ It is clear that not all patients will respond to metho- trexate. In some patients we did not see a response but were able to reduce the dosage of prednisone. Our overall response rate in that study was $66 \%$. In a follow up report of 209 patients treated for at least six months with methotrexate $52 \%$ appeared to be in remission and $16 \%$ were stable on methotrexate with or without low dose prednisone. ${ }^{33}$ In a separate report patients with neurosarcoidosis who were treated with various agents were analysed. Methotrexate was given to 28 of these patients and a response was seen in $61 \% .^{13}$

The long standing use of methotrexate for malignancy, rheumatoid arthritis, and psoriasis has given an understanding of the toxicity of the drug. There appear to be four major categories of toxicity: haematological, gastrointestinal, pulmonary, and hepatic. ${ }^{18}{ }^{34}$ There does not seem to be a particular toxicity in sarcoidosis patients that has not been reported in the other groups, although the frequency of haematological and hepatic toxicity may be higher in sarcoidosis patients because of underlying organ involvement.

Sarcoidosis can affect the bone marrow..$^{35-37}$ The toxicity can be the result of mechanical disruption of the marrow by granulomas as well as an indirect effect from the various cytokines released. Serial studies of patients with sarcoidosis have shown one or more haematological abnormalities in over half of the cases. ${ }^{35}{ }^{38}$ Lymphopenia is the most common abnormality. Significant anaemia is seen in $20 \%$ of cases and leukopenia occurs in $10 \%$ of cases. The reduction of the neutrophil count below 3000 cells $/ \mathrm{cm}^{3}$ can lead to problems when giving a bone marrow suppressive agent such as methotrexate. However, monitoring of the white blood count on a regular basis is usually sufficient to avoid this complication.

Methotrexate can cause mucositis as well as nausea and even vomiting. ${ }^{18}{ }^{34}$ This is a dose dependent effect, although there is enough variation in patient sensitivity that one can see toxicity even at the low doses used for sarcoidosis. Folate is a useful antidote for the toxicity of methotrexate and does not appear to inhibit the benefit of the drug. In one study of patients with rheumatoid arthritis the routine use of folate significantly reduced toxicity from

Table 2 Summary of reports of methotrexate for sarcoidosis

\begin{tabular}{|c|c|c|c|c|}
\hline Reference & $\begin{array}{l}\text { Patients } \\
\text { treated }\end{array}$ & Response & Other drugs & Major organs \\
\hline Lacher $^{16}$ & 1 & 1 & Prednisone tapered off & Lungs, skin \\
\hline Veien $^{51}$ & 16 & $\begin{array}{l}12 / 16 \text { with skin, } 3 / 4 \\
\text { with eye }\end{array}$ & None & Skin, lungs, eye \\
\hline Fenton $^{52}$ & 1 & 1 & Prednisone tapered & Nasal, skin \\
\hline Lower $^{23}$ & 15 & $\begin{array}{l}\text { Lungs in } 9 / 15 \text {, skin } 3 / 3 \text {, } \\
\text { liver } 2 / 2\end{array}$ & Prednisone tapered in $9 / 10$ & Lung, liver, skin, \\
\hline Soriano $0^{53}$ & 1 & 1 & Prednisone discontinued & Neurological, Heerfordt's \\
\hline Webster $^{54}$ & 3 & 3 & Intralesional corticosteroids & Skin \\
\hline Chittock $^{55}$ & 1 & 1 & Prednisone tapered & Pleural \\
\hline Henderson ${ }^{56}$ & 1 & 1 & No & Laryngeal, cutaneous \\
\hline Rajendran $^{57}$ & 12 & Excellent 7, good 4 & Four good responders on prednisone & Skin \\
\hline Lower $^{32}$ & 50 & $\begin{array}{l}\text { Lung in } 17 / 50 \text {, skin in } \\
16 / 17 \text {, eye in } 2 / 2\end{array}$ & Prednisone tapered in 29/33, 16 tapered off & Lungs, skin, eyes \\
\hline Lennarson $^{58}$ & 1 & 1 & Prednisone tapered & Eye \\
\hline Kaye $^{59}$ & 5 & 5 & Prednisone tapered in 4 of 4 & Musculoskeletal, liver \\
\hline Agbogu $^{60}$ & 3 & 1 & Prednisone tapered & Neurological \\
\hline $\mathrm{Pia}^{29}$ & 11 & 11 & Corticosteroids, cyclosporin & Lung, skin, arthritis \\
\hline Gedalia $^{30}$ & 7 & Complete 5 , partial 1 & Prednisone for four weeks only in 6 of 7 & Skin, joints, eye, lung \\
\hline Lower $^{13}$ & 28 & 17 & Prednisone tapered in all & Neurological \\
\hline Morishita $^{61}$ & 9 & 5 & Prednisone & Cardiac \\
\hline
\end{tabular}


Table 3 Response rate to prolonged treatment with methotrexate in 50 patients with sarcoidosis ${ }^{32}$

\begin{tabular}{lll}
\hline Organ involved & $\begin{array}{l}\text { No.with } \\
\text { involvement }\end{array}$ & $\begin{array}{l}\text { No. (\%) } \\
\text { responding }\end{array}$ \\
\hline Lung & 47 & $22(47)$ \\
Skin & 17 & $16(94)$ \\
Liver & 7 & $3(43)$ \\
Nervous system & 7 & $3(43)$ \\
Joints & 3 & $3(100)$ \\
Any organ & 50 & $33(66)$ \\
\hline
\end{tabular}

*Patients could have more than one organ involved.

methotrexate. ${ }^{39}$ We do not usually start with folate because over half of our patients tolerate the methotrexate without having to use it. If the patient develops any gastrointestinal symptoms we give the dose in a split manner (half one day, half the next) and add oral folate. This can be done either as a single agent $(1 \mathrm{mg} /$ day $)$ or as part of a multivitamin supplement. Many vitamins contain only relatively small amounts of folate in order to avoid masking signs of pernicious anaemia. Prenatal vitamins contain a relatively larger dose of folate and we tend to use these in patients as a general multivitamin supplement.

Hypersensitivity pneumonitis has been associated with methotrexate therapy. ${ }^{40-42}$ The risk is associated with the cumulative dose and some reports suggest that as many as $5 \%$ of patients on chronic therapy can develop hypersensitivity pneumonitis. Since sarcoidosis affects the lung in $90 \%$ of patients, there may be confusion regarding pulmonary toxicity. Fortunately, pulmonary toxicity from methotrexate is usually dose dependent, occurring after months to years of treatment. Patients with pulmonary sarcoidosis are usually being followed with serial chest radiographs and pulmonary function studies. A worsening of pulmonary symptoms in a patient who has been on methotrexate warrants evaluation. If no other cause such as infection can be found, consideration should be given to stopping the drug and seeing if symptoms are relieved. In over 200 patients treated we have seen three patients with possible methotrexate pulmonary toxicity. ${ }^{32}$ All three cases had cough associated with the drug that resolved with discontinuation of the drug and treatment with corticosteroids. All patients developed cough again when rechallenged with methotrexate. None of the cases developed definite worsening of their pulmonary function or chest radiograph. We presume that the patients were treated prior to the development of a complete hypersensitivity pneumonitis. However, cough and obstructive disease have been reported as a distinct pulmonary toxicity from methotrexate. ${ }^{43}$

The major toxicity associated with long term methotrexate use is hepatotoxicity..$^{20}$ This problem has been well appreciated and guidelines have been established in patients taking chronic methotrexate. ${ }^{22}$ The most conservative is to re-evaluate the patient after each gram of cumulative therapy. We have chosen this approach in our patients. We usually withdraw the drug at each gram of cumulative dose (approximately every two years). If the patient remains stable, nothing further is required. If symptoms occur the drug is reinstituted to determine whether the patient will respond to methotrexate. If the patient improves (usually within two months) then a liver biopsy is performed to determine whether the patient can remain on the drug. If methotrexate toxicity is seen the drug is withdrawn. Of the first 90 liver biopsy specimens we have taken, nine had evidence of methotrexate toxicity and the drug was withdrawn in all cases. None went on to develop irreversible liver damage.

Given the concerns about the hepatic toxicity of methotrexate, the question is why not perform liver function tests? We do measure liver function on a regular basis but find that liver toxicity is not easily predicted on the basis of any of the liver function tests. ${ }^{32}$ Figure 1 summarises the results of liver function tests in 27 patients undergoing liver biopsy after two or more years of treatment with methotrexate. The biopsy results of nine patients with methotrexate toxicity are compared with those of nine patients with sarcoidosis in their liver and nine patients with neither sarcoidosis nor methotrexate toxicity. The highest abnormal liver function test result for each patient in each group is shown. As can be seen, there was considerable overlap between the three groups. Thus, no liver function test abnormality predicted disease. If a patient develops marked worsening of liver function then methotrexate should be evaluated. The presence of liver disease due to sarcoidosis is not a contraindication to treatment with methotrexate. In our patients with liver involvement from sarcoidosis we have found that methotrexate may improve the liver function tests. Methotrexate has also been used for idiopathic granulomatous hepatitis. ${ }^{45}$

Other toxicities should be considered with methotrexate use. The drug is clearly teratogenic and has been shown to cause spontaneous abortions in early pregnancies. Patients (both male and female) should be advised to use adequate birth control for up to six months after discontinuation of the drug. Although there is some concern that methotrexate can cause malignancy, ${ }^{46}$ several large series have failed to show an increase in malignancy in patients treated with methotrexate and followed for up to 10 years. ${ }^{47}{ }^{48}$ This type of long term carcinogenic study has not yet been reported in patients with sarcoidosis.

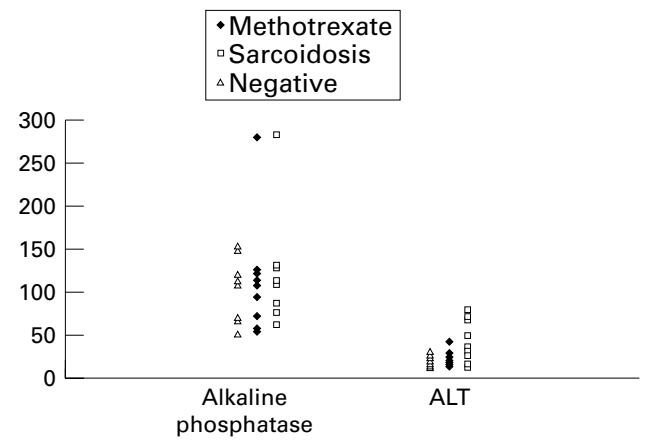

Figure 1 The highest abnormality of alkaline phosphatase and alanine aminotransferase $(A L T)$ levels in patients undergoing liver biopsy after two years of treatment with methotrexate. Patients were classified as either being negative $(\triangle)$, having methotrexate toxicity ( $\bullet$ ), or sarcoidosis involvement ( $\square$ ). 


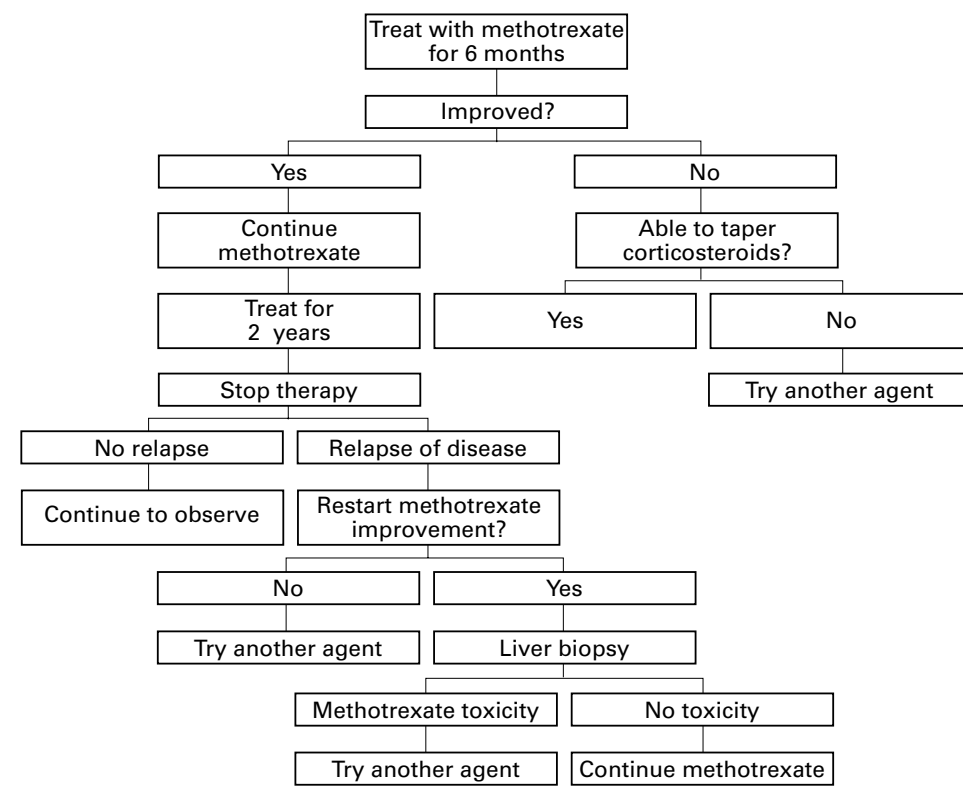

Figure 2 Approach of University of Cincinnati Interstitial Lung Disease Clinic to the management of patients started on methotrexate.

Given the above information, our approach to the use of methotrexate in patients with sarcoidosis is summarised in fig 2 . The typical patient has been on corticosteroids for more than a year, usually two. The patient who can be controlled with low doses of corticosteroids of less than $10 \mathrm{mg} /$ day prednisone or its equivalent is usually not considered a candidate for treatment with methotrexate. Some patients will refuse to continue corticosteroids at any dose, and they are also candidates for methotrexate. Rarely, patients with severe problems with corticosteroids and systemic symptoms associated with prolonged disease will be treated with methotrexate. Patients are usually started on $10 \mathrm{mg}$ per week of the drug orally. Intramuscular administration may be cheaper in some situations, but the dose should be reduced by half. The patient is seen every $4-6$ weeks.

The complete blood count is checked for white blood cells and platelet numbers. If the white blood cells drop below $3000 / \mathrm{mm}^{3}$ then we reduce the dose by half. In patients who are neutropenic to begin with, the starting dose is reduced and the patient monitored to be sure that the absolute neutrophil count does not go below 1000 cells $/ \mathrm{mm}^{3}$. The platelets may also decrease with treatment but will respond to lowering the dosage.

Methotrexate is excreted by the kidney and the serum creatinine levels should therefore be monitored. A concern has been raised in the rheumatology literature regarding the use of non-steroidal agents with methotrexate. ${ }^{49}$ Since this is a common situation in patients with chronic pain, it is not a trivial problem. However, the drug interaction appears to be caused by the effect of the non-steroidal agents on renal function, further emphasising the need for routine renal function studies. The monitoring of liver function has been alluded to earlier. We have found occasional transient increases in liver enzymes if blood is sampled the day after administration of methotrexate. We therefore try to measure liver function before the next dosage of the drug.

For the first six months of treatment with methotrexate the drug seems to have little effect on the disease. Patients who are on corticosteroids at the start of methotrexate treatment are usually maintained on the same dose until six months have passed. At that time, tapering of the corticosteroids usually begins. In most, but not all, patients the corticosteroids can be discontinued. The patient continues on treatment for two years, at which time methotrexate is withdrawn as discussed above. About $20 \%$ of patients will remain stable. For those who become symptomatic again, methotrexate is reinstituted as before. Patients will usually improve within two months, or longer if they have been off the drug for a longer period. If they do improve then a liver biopsy sample is taken. Our experience is that $10 \%$ of patients will have changes consistent with methotrexate toxicity and the drug is therefore withdrawn. For the remainder methotrexate can be given for two more years until the next liver biopsy sample is taken. We have several patients from whom three or more liver biopsy samples have been taken who have shown no evidence of methotrexate toxicity.

Future studies in patients with sarcoidosis may help to clarify the role of the drug. Since methotrexate is well tolerated by patients a double blind, randomised trial comparing methotrexate with placebo can be performed. A randomised, double blind study comparing methotrexate with placebo was carried out in patients with acute disease and showed a modest steroid sparing effect. ${ }^{50}$ However, the more important role of methotrexate appears to be for chronic disease so future research should include a study of methotrexate versus placebo in patients with chronic disease. Another important question is whether methotrexate, azathioprine, or hydroxychloroquine are equally steroid sparing. ${ }^{10}$ Finally, it is not clear whether combinations of immunosuppressants may not be better than any single agent. ${ }^{29}$

In conclusion, methotrexate represents an acceptable alternative to corticosteroids in patients with sarcoidosis. This drug should be considered in the patient with chronic or refractory disease. The acceptance rate among patients is high, reflecting its better toxicity profile compared with prednisone. It is not the perfect agent and is certainly not for every patient with sarcoidosis. However, it can be useful for many patients.

Supported in part by National Institutes of Health grant NO1HR-56069.

\footnotetext{
1 Gibson GJ, Prescott RJ, Muers MF, et al. British Thoracic Society Sarcoidosis study: effects of long term corticosteroid treatment. Thorax 1996;51:238-47.

2 Hunninghake GW, Gilbert S, Pueringer R, et al. Outcome of the treatment for sarcoidosis. Am $\mathcal{F}$ Respir Crit Care Med 1994;149:893-8.

3 Gottlieb JE, Israel HL, Steiner RM, et al. Outcome in sarcoidosis. The relationship of relapse to corticosteroid therapy. Chest 1997;111:623-31.

4 Rizzato G, Montemurro L, Colombo P. The late follow-up Rizzato G, Montemurro L, Colombo P. The late follow-up
of chronic sarcoid patients previously treated with corticoof chronic sarcoid patients previou.
steroids. Sarcoidosis 1998;15:52-8.
} 
5 Israel HL, Fouts DW, Beggs RA. A controlled trial of prednisone treatment of sarcoidosis. Am Rev Respir Dis nisone treatment

6 Baughman RP, Lower EE, Lynch JP. Treatment modalities for sarcoidosis. Clin Pulmonol Med 1994;1:223-31.

7 Neville E, Walker AN, James DG. Prognostic factors predicting the outcome of sarcoidosis: an analysis of 818 patients. Q F Med 1983;208:525-33.

8 Scadding JG. Prognosis of intrathoracic sarcoidosis in England. BMF 1961;4:1165-72.

9 Rizzato G, Fraioli P, Montemurro L. Nephrolithiasis as a presenting feature of chronic sarcoidosis. Thorax 1995;50: 555-9.

10 Baughman RP, Lower EE. Steroid-sparing alternative treatments for sarcoidosis. Clin Chest Med 1997;18:853-64.

11 Baughman RP, Winget DB, Bowen EH, et al. Predicting respiratory failure in sarcoidosis patients. Sarcoidosis 1997;14: piratory

12 Gideon NM, Mannino DM. Sarcoidosis mortality in the United States 1979-1991: an analysis of multiple-cause United States 1979-1991: an analysis of

13 Lower EE, Broderick JP, Brott TG, et al. Diagnosis and management of neurologic sarcoidosis. Arch Intern Med management of neur

14 Israel HL. The treatment of sarcoidosis. Postgrad Med $\mathcal{F}$ 1970;46:537-40

15 Lynch JPI, McCune WJ. Immunosuppressive and cytotoxic pharmacotherapy for pulmonary disorders. Am f Respi Crit Care Med 1997;155:395-420.

16 Lacher MJ. Spontaneous remission response to methotrexate in sarcoidosis. Ann Intern Med 1968;69:1247-8.

17 James DG, Jones Williams W. Sarcoidosis and other granulomatous disorders. Philadelphia: Saunders, 1985: 148-51.

18 Kremer JM, Lee JK. The safety and efficacy of the use of methotrexate in long-term therapy for rheumatoid arthritis. Arthritis Rheum 1986;29:822-31.

19 Anderson PA, West SG, O'Dell JR, et al. Weekly pulse methotrexate in rheumatoid arthritis. Ann Intern Med 1985;103: 489-96.

20 Tolman KG, Clegg DO, Lee RG, et al. Methotrexate and the liver. I Rheumatol 1985;12:S29-34.

21 Williams HJ, Wilkens RF, Samuelson CO, et al. Comparison of low-dose oral pulse methotrexate and placebo in the treatment of rheumatoid arthritis. Arthritis Rheum 1985;28 721-30.

22 Kremer JM, Alarcon GS, Lightfoot RW Jr, et al. Methotrexate for rheumatoid arthritis. Suggested guidelines for monitoring liver toxicity. American College of Rheumatology. Arthritis Rheum 1994;37:316-28.

23 Lower EE, Baughman RP. The use of low dose methotrexate in refractory sarcoidosis. Am f Med Sci 1990;299:1537 .

24 Baughman RP, Lower EE. The effect of corticosteroid or methotrexate therapy on lung lymphocytes and macrophages in sarcoidosis. Am Rev Respir Dis 1990;142:126871 .

25 Thomas PD, Hunninghake GW. Current concepts of the pathogenesis of sarcoidosis. Am Rev Respir Dis 1987;135. pathogenes

26 Hunninghake GW, Crystal RG. Pulmonary sarcoidosis: a disorder mediated by excess helper T-lymphocyte activity at sites of disease activity. N Engl f Med 1981;305:429-32.

27 Baughman RP, Strohofer SA, Buchsbaum J, et al. Release of tumor necrosis factor by alveolar macrophages of patients with sarcoidosis. F Lab Clin Med 1990;115:36-42.

28 Pueringer RJ, Schwartz DA, Dayton CS, et al. The relationship between alveolar macrophage TNF, IL-1, and PGE release, alveolitis, and disease severity in sarcoidosis. Chest 1993;103:832-8.

29 Pia G, Pascalis L, Aresu G, et al. Evaluation of the efficacy and toxicity of the cyclosporine A-flucortolonemethotrexate combination in the treatment of sarcoidosis. Sarcoidosis Vasc Diffuse Lung Dis 1996;13:146-52.

30 Gedalia A, Molina JF, Ellis GS, et al. Low-dose methotrexate therapy for childhood sarcoidosis. F Pediatr 1997;130: 25-9.

31 Feagan BG. Methotrexate therapy for chronic sarcoidosis: is the therapeutic index acceptable? F Pediatr 1997;130:3-4.

32 Lower EE, Baughman RP. Prolonged use of methotrexate for sarcoidosis. Arch Intern Med 1995;155:846-51.

33 Baughman RP, Lower EE. Alternatives to corticosteroids in the treatment of sarcoidosis. Sarcoidosis 1997;14:121-30.
34 Weinblatt ME. Toxicity of low dose methotrexate in heumatoid arthritis. I Rheumatol 1985;12:S35-9.

35 Lower EE, Smith JT, Martelo OJ, et al. The anemia of sarcoidosis. Sarcoidosis 1988;5:51-5.

36 Kennedy D, Yamakido M. Hematologic manifestations of sarcoidosis. Semin Respir Med 1992;13:455-8.

37 Browne PM, Sharma OP, Salkin D. Bone marrow sarcoidois. $\mathcal{F} A M A 1978 ; 240: 43-50$.

38 Maycock RL, Bertrand P, Morrison CE. Manifestations of sarcoidosis. Am f Med 1963;35:67-89.

39 Morgan SL, Baggott JE, Vaughn WH, et al. Supplementation with folic acid during methotrexate therapy for tion with folic acid during methotrexate therapy for

40 Sostman HD, Matthay RA, Putman GE. Methotrexateinduced pneumonitis. Medicine 1976;55:371-88.

41 Hargreaves MR, Mowat AG, Benson MK. Acute pneumonitis associated with low dose methotrexate treatment for rheumatoid arthritis: report of five cases and review of published reports. Thorax 1992;47:628-33.

42 White DA, Rankin JA, Stover DE, et al. Methotrexate pneumonitis: bronchoalveolar lavage findings suggest an immunologic disorder. Am Rev Respir Dis 1989;139:18-21.

43 Jones G, Mierins E, Karsh J. Methotrexate-induced asthma. Am Rev Respir Dis 1991;143:179-81.

44 Van de Kerkhof PCM, Hoefnagels WHL, van Haelst JGM, et al. Methotrexate maintenance therapy and liver damage in psoriasis. Clin Exp Dermatol 1985;10:194-200.

45 Knox TA, Kaplan MM, Gelfand JA, et al. Methotrexate reatment of idiopathic granulomatous hepatitis. Ann Intern Med 1995;122:592-5.

46 Balin PL, Tindall JP, Roenigk $\mathrm{HH}$, et al. Is methotrexate therapy for psoriasis carcinogenic? A modified
retrospective-prospective analysis. $尹 A M A$
$1975 ; 232: 359-$ 62.

47 Rustin GJS, Rustin F, Dent J, et al. No increase in second tumors after cytotoxic chemotherapy for gestational trophoblastic tumors. N Engl F Med 1982;308:473-6.

48 Nyfors A, Jensen H. Frequency of malignant neoplasms in 248 long-term methotrexate treated psoriatics. Dermatologica 1983;167:260-1

49 Wallace CA, Smith AL, Sherry DD. Pilot investigation of naproxen/methotrexate interaction in patients with juvenile rheumatoid arthritis. F Rheumatol 1993;20:1764-8.

50 Baughman RP, Winget DB, Lower EE. Prospective, randomized, double blind trial of methotrexate as a steroid sparing agent for sarcoidosis: analysis of first 25 patients. Am $\mathcal{F}$ Respir Crit Care Med 1997;155:A944

51 Veien NK, Brodthagen H. Cutaneous sarcoidosis treated with methotrexate. Br f Dermatol 1977;97:213-6.

52 Fenton DA, Shaw M, Black MN. Invasive nasal sarcoidosis reated with methotrexate. Clin Exp Dermatol 1985;10:279-

53 Soriano FG, Caramelli P, Nitrini R, et al. Neurosarcoidosis: therapeutic success with methotrexate. Postgrad Med $\mathcal{F}$ 1990;66:142-3.

54 Webster GF, Razsi LK, Sanchez M, et al. Weekly low-dose methotrexate therapy for cutaneous sarcoidosis. $\mathcal{F} \mathrm{Am} \mathrm{Acad}$ Dermatol 1991;24:451-4

55 Chittock DR, Joseph MG, Paterson NA, et al. Necrotizing sarcoid granulomatosis with pleural involvement. Clinical and radiographic features. Chest 1994;106:672-6.

56 Henderson CA, Ilchyshyn A, Curry AR. Laryngeal and cutaneous sarcoidosis treated with methotrexate. $\mathcal{F} R$ Soc Med 1994;87:632-3.

57 Rajendran R, Theertham M, Salgia R, et al. Methotrexate in the treatment of cutaneous sarcoidosis. Sarcoidosis 1994;11: S335-8.

58 Lennarson P, Barney NP. Interstitial keratitis as presenting ophthalmic sign of sarcoidosis in a child. F Pediatr Ophthal mol Strabismus 1995 May-Jun 1996;32:194-6.

59 Kaye O, Palazzo E, Grossin $M$, et al. Low-dose methotrexate: an effective corticosteroid-sparing agent in the musculoskeletal manifestations of sarcoidosis. $\mathrm{Br} f$ Rheumatol 1995;34:642-4.

60 Agbogu BN, Stern BJ, Sewell C, et al. Therapeutic considerations in patients with refractory neurosarcoidosis. Arch Neurol 1995;52:875-9.

61 Morishita M, Matsuda R, Satoh S, et al. Prolonged low dose methotrexate for cardiac sarcoidosis. Am $\mathcal{F}$ Respir Crit Care Med 1998;157:A809. 